\title{
A Ricardian Analysis of the Impact of Temperature and Rainfall Variability on Agriculture in Dosso and Maradi Regions of Niger Republic ${ }^{1}$
}

\author{
Garba Hima Mamane Bello, Maman Nafiou Malam Maman \\ Department of Economics, University of Abdou Moumouni, Niamey, Niger \\ Email: $\underline{\text { mbello.hima@yahoo.fr, mnafiou@yahoo.fr }}$
}

Received 11 February 2015; accepted 26 July 2015; published 29 July 2015

Copyright (C) 2015 by authors and Scientific Research Publishing Inc.

This work is licensed under the Creative Commons Attribution International License (CC BY).

http://creativecommons.org/licenses/by/4.0/

\section{(c) (i) Open Access}

\begin{abstract}
The impact of climate variability on Maradi and Dosso agriculture was estimated taking into account farmer adaptations. The study used a Ricardian analysis of 200 farms to explore the effects of climate variability on net revenue. It also simulates the impact of different climate scenarios on agriculture incomes. This analysis bespeaks that if temperature increases $1^{\circ} \mathrm{C}$ annually, the annual crop net revenues for both frameworks will decrease up to 582170.7 FCFA $^{2}$ for model without adaptation (M1) and up to 1316 FCFA for model with adaptation (M2). An increase of Precipitation of $1 \mathrm{~mm} /$ month will increase crop receipts for the frameworks up to 721,917 FCFA for M1 and $1,861,455$ FCFA for M2. In order to predict climate change impacts for these regions, the RCP 4.5 and RCP 8.5 of IPCC scenarios were examined. The crop net receipts will fall between $10 \%$ and $26 \%$ if the scenarios happen. Another finding of this study is that each farmer who is practicing adaptation is able to cover the potential loss from climate variability up to $8.95 \%$ and $12.71 \%$ per ha respectively in Maradi and in Dosso. The study proposes that these regions should start planning measures for unexpected event of climate conditions. Irrigated systems need to be encouraged in order to minimize the vulnerability of the agricultural sector.
\end{abstract}

\section{Keywords}

Agriculture, Maradi, Dosso, Niger Republic, Ricardian Analysis

${ }^{1}$ This research paper is financed by the West African Science Service Centre for Climate Change and Adapted Land Use (WASCAL) programme.

${ }^{2} 500 \mathrm{FCFA}=\$ 1$.

How to cite this paper: Mamane Bello, G.H. and Malam Maman, M.N. (2015) A Ricardian Analysis of the Impact of Temperature and Rainfall Variability on Agriculture in Dosso and Maradi Regions of Niger Republic. Agricultural Sciences, 6, 724-733. http://dx.doi.org/10.4236/as.2015.67070 


\section{Introduction}

Located in West Africa, Niger is one of the Sahelian countries whose geographical position, the climate and natural environment are harsh. The rainfall is low and characterized by strong inter-annual and space-time variability. This directly affects agro-pastoral production. The Niger economy is heavily dependent on agriculture. Reference [1] reported that from 1960 to 2010 , on average $80 \%$ of the population was primarily employed in agriculture, which accounted for $40 \%$ of Niger's GDP, so changes in temperature and precipitation could seriously damage the nation's economy. Niger agriculture is a subsistence agriculture based on cereal growing (millet, sorghum, maize, and beans) which takes up $90 \%$ of the cultivated area per year and constitutes the staple diet of the majority of the population. The soils are generally not very deep, with low water retention capacity and low organic matter content. Wind erosion is becoming exhausted, causing a decrease in yields in these regions. The agricultural lands are becoming further degraded from year to year because of traditional farming methods and population growth, notably near the urban centers. These physical and climatic constraints make Niger agriculture vulnerable, as crops are essentially rain-fed. Vulnerability due to climatic hazards, the inadequate growth of productivity and the poor diversification of incomes are the reasons why economic and food insecurity persist in the rural households. The climatic hazards which affect the stability of agro-pastoral production and export incomes are weakening the country's economy.

Objectives are to: 1) quantify the impact of climate variability on agriculture net income in Dosso and Maradi regions; 2) evaluate the effect of climate change on revenue on the basis of the IPCC climatic changes' scenarios; 3) determine factors explaining the vulnerability of the agricultural systems in those regions; 4) determine approaches for adaptive mechanisms.

The rest of the work is organized as follows. Section 2 reviews the literature on approaches for the assessment of impacts on agriculture with emphasis on the Ricardian method. Section 3 presents the methodology used. It describes how the Ricardian approach is adapted for the analysis in this paper, and the modeling approach. Section 4 presents the estimation and results. Finally, the economic policy implications and conclusions are presented in section 5 .

\section{Review of Literature}

The methods used to assess the impact of climate change on agricultural net revenue can be grouped in two main categories [2]: the structural modeling of the agronomic response based on controlled experiments (the production function approach), and modeling taking into account the link between crop production and the farmers' economic management decisions, based on theoretical specification (the Ricardian approach).

\subsection{Crop Production Function}

Production function model generally links the outputs of crops or livestock as functions of inputs to the production process, such as land, labor, and capital and entrepreneurship skill. While the production function approach is the least common approach used to model the impacts of climate change on agricultural outputs to date, it is empirically sound. Reference [3] reported that the production function approach provides estimates of weather effects on crop yields that do not include bias due to agricultural output factors that are beyond farmers' control such as soil quality. On the other hand, these authors noted that a disadvantage is that production function estimates do not account for the full range of adaptation responses that farmers can make to changes in weather in order to maximize their profits. Since farmer adaptations are completely constrained in the production function approach, it is likely to produce estimates of climate change that are biased downwards. One advantage of the production function approach is that historical farm-level and aggregated data takes into account farmers' historical reactions to changes in climatic and economic conditions. However, this historical data is not able to capture future plant-climate interactions in a sufficient manner, especially where the crop-weather relationship is restricted to a few variables such as temperature and rainfall. In addition, these models cannot sufficiently integrate expected $\mathrm{CO}_{2}$ fertilization effects on plants due to low variation in historical $\mathrm{CO}_{2}$ concentrations [4]. This approach can assess the impact of low to very low factor variations; however it overestimates the damage to crop yields due to climate change. Reference [5], call this bias as the "dumb farmer scenario", in other words, it does not take into account farmers' adaptations as a response to social, economic and environmental changes. 
Indeed, most of the studies using this model do not take into account farmers' adaptations but simply assess one or several factors involved in crop yield. The Ricardian approach, however, compensates for the bias in the production function approach.

\subsection{The Ricardian Approach}

By far, most of the literature has focused on the use of Ricardian Models. These models look at the impact of climate change on farm land value or net farm income. Theoretically, it is assumed that changes in farm output in terms of the quantity of products or the value of products, together with the opportunity cost of the land is reflected in the farm's land value. Farmland net revenues reflect net productivity. In addition, "the value of a parcel of land should reflect its potential profitability, implying that spatial variations in climate drive spatial variations in land uses and in turn land values" (David Ricardo 1772-1823). The advantage is that if land markets are operating properly, prices will reflect the present discounted value of land rents into the infinite future [6]. In some developing countries such as Kenya [7], Egypt [8], South Africa ([9] and [10]), Senegal [11], Zambia [12], Zimbabwe [13], Ethiopia [14], and India ([15] and [16]), the Ricardian approach has been applied to examine the sensitivity of agriculture to changes in climate. It was mainly used to assess economic impacts of climate change on agriculture in the above African countries by regressing net revenue (or crop net revenue) per hectare as response variable with climate (temperature and precipitation), hydrological, soils and socio-economic variables taken as explanatory variables. The references [17]-[19] described that the value of a parcel of land in a well-functioning market system should reflect its potential profitability. One of the weaknesses of the Ricardian approach is that it is not based on controlled experiments across farms. Farmers' responses vary across space not only because of climatic factors, but also because of many socio-economic conditions.

\section{Methodology}

The Ricardian method is a cross-sectional approach studying agricultural production. It is based on land rent which is seen as the net revenue from the best use of land. The land rent would reflect the net productivity of farm land. Farm value $(V)$ consequently reflects the present value of future net productivity. The principle is captured by the following equations [20].

$$
\begin{gathered}
V_{L}=\int_{0}^{\infty} P_{L} \mathrm{e}^{\delta t} \mathrm{~d} t \\
=\int_{0}^{\infty}\left[\frac{P_{i} Q_{i}^{*}\left(K_{i}, E\right)-C_{i}^{*}\left(Q_{i}^{*}, W, E\right)}{L_{i}}\right] \mathrm{e}^{\delta t} \mathrm{~d} t
\end{gathered}
$$

The farmer is assumed to choose $K$ to maximize net revenues given the characteristics of the farm and market prices.

The standard Ricardian model relies on a quadratic formulation of climate:

$$
V=B_{0}+B_{1} F+B_{2} F^{2}+B_{3} Z+B_{4} G+u
$$

where: $F=$ vector of climate variables; $Z=$ set of soil variables; $G=$ set of socio-economic variables; $u=$ an error term, $F$ And $F^{2}$ capture, respectively, linear and quadratic terms for temperature and precipitation. The introduction of quadratic terms for temperature and precipitation is to seek the likely non-linear shape of the response function between net revenue and climate. From past studies one expects that farm revenues will have U-shaped or hill-shaped relationship with temperature. When the quadratic term is positive, the net revenue function is U-shaped, but if the quadratic term is negative, the function is hill shaped. For each crop, there is a known temperature where that crop grows best across the seasons though the optimal temperature varies from crop to crop [5].

From Equation (3) we can derive the marginal impact of a climate variable $\left(f_{i}\right)$ on farm revenue evaluated at the mean as follows:

$$
E\left[\mathrm{~d} V / \mathrm{d} f_{i}\right]=E\left[B_{1, i}+2 B_{2, i} * f_{i}\right]=B_{1, i}, \text { Because } E\left(f_{i}\right)=0
$$

The change in welfare, $\Delta U$, resulting from a climate change from $C_{0}$ to $C_{1}$ can be measured as follows [20]: 


$$
\Delta U=V\left(C_{1}\right)-V\left(C_{0}\right)
$$

If the change increases net income it will be beneficial and if it decreases net income it will be harmful.

\subsection{Modified Model for Dosso \& Maradi}

This paper considered for Niger Republic crop agriculture, the specification of [20], with the difference that set of soil types are not considered.

$$
V=B_{0}+B_{1} F+B_{2} F^{2}+B_{3} G+u
$$

The set of soil variables was eliminated in this equation because of non-availability in Maradi and Dosso regions.

\subsection{Empirical Models and Data}

\subsubsection{Data}

The data for the analysis is based on cross-sectional data at household and district levels. These include farm household and climate data.

1) Farm household data: Questionnaire was administered among respondents through personal interview. Respondents for the study are selected through multi-stage sampling procedure. In the first stage five districts were randomly selected from each of the two regions being considered in the study area. From each of the selected districts, one village was randomly selected, giving a total of ten villages for the study. In the third stage, twenty farming households were randomly selected from each village. The head of the selected household was taken as respondent for the study, yielding two hundred (100 in Dosso and 100 in Maradi) total respondents for the study. The data collected at household level were for the agricultural year 2012-2013.

2) Climate data: These data were collected from the National stations measurements of rainfall and minimum and maximum temperature, from 1960 to 2013.

\subsubsection{Empirical Models}

1) Functional form

According to the evidence of the results obtained by [5] and [15], and taking into account the distinctiveness of the climate of Niger Republic, the following functional forms were adopted:

$\checkmark$ The model "without" adaptation options includes only the physical variables (temperature, rainfall, and soils):

$$
\begin{aligned}
Y_{n e t, h a}= & \alpha_{0}+\alpha_{1} \text { rainy } t+\alpha_{2} \text { rainy } t^{2}+\alpha_{3} d r y_{-} t+\alpha_{4} d r y_{-} t^{2}+\alpha_{5} \text { rainy } p \\
& +\alpha_{6} \text { rainy }_{-} p^{2}+\alpha_{7} d r y_{-} p+\alpha_{8} d r y_{-} p^{2}+\mu
\end{aligned}
$$

(7) Model 1.

where rainy $t$ and rainy $p$ are the mean temperature and the total precipitation of rainy season respectively; while $d r y_{-} t$ and $d r y_{-} p$ are the mean temperature and precipitation of the dry season and $\alpha_{0}$ is an error term.

$\checkmark$ The model "with" adaptation measures includes the previous variables and farms characteristics:

$$
\begin{aligned}
Y_{n e t, h a}= & \alpha_{0}+\alpha_{1} \text { rainy_ } t+\alpha_{2} \text { rainy } t_{-}^{2}+\alpha_{3} d r y_{-} t+\alpha_{4} d r y_{-} t^{2}+\alpha_{5} \text { rainy } p \multimap \\
& +\alpha_{6} \text { rainy } p^{2}+\alpha_{7} d r y_{-} p+\alpha_{8} d r y_{-} p^{2}+\sum_{j=1}^{m} \gamma_{j} G_{j}+\mu
\end{aligned}
$$

(8) Model 2.

$G_{j}$ is the set of socio-economic variables such as: study level, household size, age, access to credit, sex, adaptation value and fallow. $\gamma_{1}, \cdots, \gamma_{j}$ are estimated coefficients and $\alpha_{0}$ is an intercept.

$\checkmark$ The model with adaptation per region

Data from each region is used separately in Equation (8) to compare results between regions.

$$
\begin{aligned}
Y_{n e t, h a}= & \alpha_{0}+\alpha_{1} \text { rainy_t } t+\alpha_{2} \text { rainy } t^{2}+\alpha_{3} d r y_{-} t+\alpha_{4} d r y_{-} t^{2}+\alpha_{5} \text { rainy } p \\
& +\alpha_{6} \text { rainy_ } p^{2}+\alpha_{7} d r y_{-} p+\alpha_{8} d r y_{-} p^{2}+\sum_{j=1}^{m} \gamma_{j} G_{j}+\mu
\end{aligned}
$$

2) Estimation procedure 
The three models were estimated by using STATA software. Different stages of the estimations were undertaken. At the first stage the climatic factors were integrated. This first sequence of variables allowed defining the model without adaptation relying only on physical factors (climate). At the second stage variables related to farm characteristics were integrated into the first model. These permitted to take farmers' adaptations into consideration and to assess their effect on the agricultural income. This second stage led to the second model, with adaptation options. At the third stage data per region were integrated into the previous model in order to compare the impact of climate change on agriculture per region.

\section{Results}

\subsection{Validation of the Model}

The Fisher-Snedecor test is used to validate the total significance of the models and the Student $\mathrm{T}$ test for the individual significance of each coefficient. The Fisher-Snedecor test shows all the regressions are all significant at $1 \%$ level. The coefficient of determination $\left(\mathrm{R}^{2}\right)$ of the model without adaptation is $41.8 \%$. Though the integration of adaptation variables improved the model (with $\mathrm{R}^{2}=44.8 \%$ ), a large part of the variation in the agricultural income remains unexplained by the variables taken into account. This is true of farms that vary from small backyard systems to large commercial operations [21].

\subsection{Regression Results}

Tables 1-3 present the results of the estimated models. The results show that the signs of seasonal climatic variables are the same for all the estimated models (model without adaptation, model with adaptation and model with adaptation and per region). The sign of quadratic terms is opposite to the sign of linear terms for the temperature and the precipitation. The relationship between revenue and temperature or precipitation is therefore non-linear. This means that temperature or precipitation affects the net revenue positively up to a certain level, above which it causes damage to the crops. The Educational level of the household head used as a proxy for literacy rate is contributing to increase his net revenue significantly up to 3102.42 FCFA per ha; while his access

Table 1. Regression results of model without adaptation (all farms).

\begin{tabular}{|c|c|c|c|}
\hline Variable & Coefficient & & $\mathbf{T}$ \\
\hline Dry season temperature & -1315.956 & $\mathrm{n}$ & 1.00 \\
\hline Dry season temperature squared & 162393.8 & ** & -1.99 \\
\hline Rainy season temperature & $2,017,934$ & $\mathrm{~N}$ & 0.56 \\
\hline Rainy season temperature squared & -32273.6 & $\mathrm{~N}$ & -0.60 \\
\hline Dry season precipitation & $2,609,024$ & $\mathrm{~N}$ & 1.48 \\
\hline Dry season precipitation squared & -89379.17 & * & -1.73 \\
\hline Rainy season precipitation & $1,861,455$ & * & -1.78 \\
\hline Rainy season precipitation squared & -6140.606 & * & 1.66 \\
\hline Age of the farmer & -2276.795 & $*$ & -1.69 \\
\hline Household size & -3168.617 & $*$ & -1.89 \\
\hline Education level & 3102.42 & $\mathrm{~N}$ & 0.53 \\
\hline Access to credit & -545.3134 & $\mathrm{~N}$ & -1.24 \\
\hline Adaptation value & 0.0886208 & * & 1.72 \\
\hline Constant & $-1.33 \mathrm{e}+08$ & $\mathrm{~N}$ & -0.64 \\
\hline Number of observations & 200 & & \\
\hline $\mathrm{F}$ & 34 & & \\
\hline R-squared & 0.448 & & \\
\hline
\end{tabular}

${ }^{*}$ Significant at $10 \%$ level; ${ }^{* *}$ Significant at $5 \%$ level $\mathrm{n}=$ not significant. 
Table 2. Regression results of model with adaptation.

\begin{tabular}{cccc}
\hline Variable & Coefficient & T & 0.48 \\
Dry season temperature & $-821,707$ & $\mathrm{n}$ & -0.47 \\
Dry season temperature squared & 77884.84 & $\mathrm{n}$ & -0.51 \\
Rainy season temperature & $1,536,771$ & $\mathrm{n}$ & 0.47 \\
Rainy season temperature squared & -21136.56 & $*$ & -1.54 \\
Dry season precipitation & 794661.7 & $* *$ & -1.66 \\
Dry season precipitation squared & -37872.23 & $\mathrm{n}$ & 0.78 \\
Rainy season precipitation & 721917.7 & $*$ & -1.81 \\
Rainy season precipitation squared & -2629.111 & $\mathrm{n}$ & -0.17 \\
Age of the farmer & -2695.248 & & \\
Constant & $-3.54 \mathrm{e}+07$ & 200 & \\
Number of observations & 9.34 & & \\
R-squared & 0.418 & & \\
\hline
\end{tabular}

"Significant at $10 \%$ level; ${ }^{* *}$ Significant at $5 \%$ level $\mathrm{n}=$ not significant.

Table 3. Regression results of model with adaptation per region.

\begin{tabular}{|c|c|c|c|c|c|c|}
\hline & Coef_Maradi & & $\mathbf{T}$ & Coef_Dosso & & $\mathbf{T}$ \\
\hline Dry season temperature & 59868.56 & * & 1.77 & 202719.8 & * & 1.81 \\
\hline Rainy season temperature & -109227.4 & ** & -2.61 & -46131.32 & ${ }^{* *}$ & -1.44 \\
\hline Dry season precipitation & 383688.6 & $\mathrm{n}$ & 0.57 & -398016.6 & $\mathrm{~N}$ & -0.79 \\
\hline Rainy season precipitation & 82513.21 & ** & -2.38 & 99229.85 & $* *$ & 2.93 \\
\hline Age of the farmer & 652.6344 & ** & 1.74 & -3498.405 & $\mathrm{~N}$ & -0.04 \\
\hline Household size & 776.4336 & ** & 1.40 & -6206.766 & $\mathrm{~N}$ & -1.03 \\
\hline Study level & 2493.575 & $\mathrm{n}$ & 0.68 & -110.6892 & $* *$ & -2.01 \\
\hline Access to credit & -693.6599 & ** & -2.13 & -201.6057 & $*$ & -1.41 \\
\hline Adaptation value & 0.08953 & ** & 2.05 & 0.1271129 & $* *$ & 2.14 \\
\hline Constant & $9,032,908$ & $\mathrm{n}$ & 0.35 & $-1.49 \mathrm{e}+07$ & $\mathrm{~N}$ & -0.62 \\
\hline Number of observations & 100 & & & 100 & & \\
\hline $\operatorname{Prob}(F, 18)$ & 0.000 & & & 0.000 & & \\
\hline R-squared & 0.448 & & & 0.412 & & \\
\hline
\end{tabular}

"Significant at $10 \%$ level; ${ }^{* *}$ Significant at $5 \%$ level $\mathrm{n}=$ not significant.

to credit is decreasing the net revenue up to 545.31 FCFA per ha. The household size used as proxy for household labor affects negatively the net revenue up to 3168.61 FCFA. This can be explained by the increase of the population to feed without possibility to increase the land, hence to increase the production. Taking into consideration the effect of climate variability, if a farmer is practicing adaptation such as trade, crop diversification, livestock raising, fallow practicing, irrigation, water harvesting etcetera, he will be able to compensate the potential adverse impact of climate variability up to $8.86 \%$ per ha. In order to interpret the climate coefficients, the marginal effects of the climate variables are estimated using equation 4 for the model "with" adaptation. Maradi's farmer who went to school is gaining excess revenue of about 2494 FCFA per hectare and for a farmer who is combining trade and farming can recompense the potential loss from climate change effect up to $8.953 \%$. But this is not significant at $5 \%$ level, and this could be explained by the fact that farmers are under estimating their 
adaptation measures. Regarding the serious adverse effect of climate change in this region, for a farmer to have access to credit is not profitable, because he will not be able to reimburse the credit and will be losing 694 FCFA per hectare. The variable "age" is positively correlated with the net revenue. This is explained by the fact that most of young people are abandoning agricultural activities and those young who are practicing agricultural activities are not having experience and skills to manage especially when the climate variations are crucial. The coefficient of the variable Education level is negatively correlated to the net revenue for Dosso region. This is true because about $95 \%$ of the sample population of this area did not school even at primary level. So they are not having any advantage of going to school. For instance a farmer is losing revenue about 110 FCFA per hectare. For a farmer who is combining trade and farming activities in Dosso can recompense the potential loss from climate change effect up to $12.71 \%$. This compensation is significant at $5 \%$ level. Regarding the harmful effect of climate change in Dosso region, it is not profitable for a farmer to have access to credit, because he will not be able to reimburse the credit and will be losing 201.60 FCFA per hectare. The variable age is negatively correlated with the net revenue. This is explaining by the fact that most young people practice irrigation over the whole year using the river Niger. That is true because the old people cannot generate more revenue in irrigation than young people.

\subsection{Marginal Effect of Climate Change on Net Revenue}

The estimated marginal effects of temperature and precipitation on crop net revenues are presented in Table 4 on per hectare basis. These tables show the net annual marginal effect of temperature and precipitation for without and with adaptation models, respectively. The net effects of the seasonal impacts for the model without adaptation indicate that a $1{ }^{\circ} \mathrm{C}$ increase in annual temperature will lead to a decrease in crop net revenue of 582170.7 FCFA for Maradi and Dosso regions. This change is not significant at 5\% level. The marginal impact of precipitation on crop net revenue indicates that an annual increase of $1 \mathrm{~mm} / \mathrm{month}$ of precipitation will have significant positive effect on net revenues. For Maradi and Dosso, an annual net gain of 721917.7 FCFA is expected. For the model with adaptation, the net effect of a $1{ }^{\circ} \mathrm{C}$ increase in temperature will decrease crop net revenues by 46131.32 FCFA (12.72\% of the average net income) for Dosso farms and 109227.4 FCFA (30.12\% of the average net income) for Maradi farms. The net effect of a $1 \mathrm{~mm} / \mathrm{month}$ increase in precipitation annually will lead to an increase in crop net revenue. A net gain of 82513.21 FCFA and 99229.85 FCFA is expected for Maradi farms and Dosso farms respectively. In both instances the estimates are also significant.

\subsection{Forecasted Scenarios}

Using the coefficients in Table 2 and uniform climate change the results of uniform climate change scenarios are presented in Table 5. The results of the scenarios indicate that an increase in temperature by $4.5^{\circ} \mathrm{C}$ will reduce crop net revenue per hectare by 35336.2 FCFA for regions combined. However, taking this loss per region, Dosso farms will lose up to 94934.16 FCFA and 31034.84 FCFA for Maradi farms. While, an $8.5^{\circ} \mathrm{C}$ increase in temperature will reduce crop net revenue by 35336.04 FCFA for regions combined, 94933.15 FCFA for Dosso farms and 31034.85 FCFA for Maradi farms. A decrease in precipitation by $7 \%$ will reduce crop net revenue by 5368.108 FCFA, 12780.09 FCFA and 627944.2 FCFA for combined regions, Maradi farms and Dosso farms, respectively. A $14 \%$ reduction in precipitation will reduce crop net revenue by -679054.4 FCFA for Dosso region. However, this reduction of precipitation up to $14 \%$ will increase the net revenue up to 9305.661 FCFA and 13820.29 FCFA, respectively, for the combined regions and Maradi land farms. This increase of revenue when precipitation decreased does not conform to the existing findings. In our case it could be explained by the expectation that if precipitation decreases seriously, Maradi farmers will abandon the rain-fed agriculture to purely irrigation agricultural activities. This expectation is based on the economists' assumption of "everything being equal" (Ceteris paribus).

Table 4. Marginal effects of climate variables on crop net revenue for model with adaptation.

\begin{tabular}{cccc}
\hline Climate variable & Full sample & Maradi & Dosso \\
\hline Temperature & $-1315.96^{*}$ & $-109,227^{*}$ & $-46131.32^{* *}$ \\
Precipitation & $1,861,455^{* *}$ & $82513.21^{* * *}$ & $99,230^{* *}$ \\
\hline
\end{tabular}

\footnotetext{
"Significant at $10 \%$ level; ${ }^{* *}$ Significant at $5 \%$ level; ${ }^{* * *}$ Significant at $1 \%$ level.
} 
Table 5. Impacts from uniform climate scenarios on net crop revenue.

\begin{tabular}{cccc}
\hline Climate change scenarios & Full sample & Maradi & Dosso \\
\hline$+4.5^{\circ} \mathrm{C}$ in temperature \\
$\begin{array}{c}\text { Change crop net revenue } \\
\quad \text { FCFA/hectare) } \\
+8.5^{\circ} \mathrm{C} \text { in temperature } \\
\begin{array}{c}\text { Change crop net revenue } \\
\quad \text { (FCFA/hectare) }\end{array}\end{array}$ & -35336.2 & -31034.84 & -94934.16 \\
$\begin{array}{c}7 \% \text { reduction in precipitation } \\
\text { Change crop net revenue } \\
\quad \text { (FCFA/hectare) }\end{array}$ & -35336.04 & -31034.85 & -94933.15 \\
$\begin{array}{c}14 \% \text { reduction in precipitation } \\
\text { Change crop net revenue } \\
\text { (FCFA/hectare) }\end{array}$ & -5368.108 & -12780.09 & -627944.2 \\
\hline
\end{tabular}

\section{Discussions}

The econometric results illustrate that increased temperatures and a decrease in precipitation would negatively affect crop yields over the two main regions of crop agriculture in Niger Republic. Indeed, yields in Maradi and Dosso regions would decrease by $26 \%$ with a $1{ }^{\circ} \mathrm{C}$ temperature increase and $10 \%$ precipitation decrease for instance. The result per region permits to analyze which area is more sensitive to an increase or decrease in a specific climatic variable. The main findings from the survey demonstrated which socio-economic variables are important according to the farmers, such as input costs, input availability and lack of labor. The survey also showed that indeed, Nigeriens farmers have perceived changes in climate and that accordingly changes in climate are negatively affecting their yields. The results further showed that climate exhibits a nonlinear relationship with net revenue, which is consistent with available literature [5] [20] [22]. The S. Fisher test results showed that the overall models are significant at the $1 \%$ level, and the $\mathrm{R}^{2}$ is explaining that the independent variables of the models explained between $44.18 \%$ and $44.25 \%$ of the net revenue.

\section{Conclusions}

This investigation explores the impact of climate on crop revenue in Dosso and Maradi regions of Niger Republic using the Ricardian model. The work used primary households level data enriched with secondary climate data. Most of the results show that increasing temperature and decreasing rainfall are damaging to the crop agriculture. Increased wet period temperature increased net crop revenue up to certain level and then became harmful, while high dry period temperatures had a negative impact on crop revenue. Increased precipitation during wet period had the impact of increasing net crop revenue, but when it exceeded the threshold, flood would then follow. The results further showed that there was a non-linear relationship between temperature and crop revenue on one hand and between precipitation and crop revenue on the other hand. The analysis of perceptions and adaptation of farmers to climate change show that farming households in Niger Republic are aware of both short term and long term climate change and some have implemented various adaptation mechanisms to climate variations. Irrigation practice is the most common adaptation measure $(26 \%)$, more so in Dosso region, while livestock rising and changes in crop mix (diversification) and planting trees are used in both regions.

The work is contributing to the existing knowledge in the sense that: first, it has specifically assessed the amount at which a farmer can compensate his loss, if practicing adaptation; second, the study finds a level at which a farmer may decide to abandon the rain-fed agricultural activities.

\section{Recommendation}

The following recommendations are listed as adaptation measures to counteract the harmful impacts of climate change.

$>$ Management of the scarce water resources in the country could generate more water for irrigation purposes especially in Maradi region;

$>$ Expansion of new varieties of crops and diversification from traditional crops to other types of crops which 
can with stand drought and higher temperature;

> Policies that improve household welfare as well as access to credit with simple and very low rate are also a priority for both short term and long term adaptation measures.

There is also need to carry this research over the whole county so that the conclusions and results will not be too much bias.

\section{References}

[1] INS, Niger (2010) Annuaire statistique des cinquante ans d'Independence du Niger, édition spéciale 2010. Institut National de la Statistique du Niger, 257, 259-277.

http://www.stat-niger.org/statistique/file/Annuaires Statistiques/Annuaire ins 2010/serie longue.pdf

[2] Ouedraogo, M., Somé, L. and Dembele, Y. (2006) Economic Impact Assessment of Climate Change on Agriculture in Burkina Faso: A Ricardian Approach. CEEPA Discussion Paper No. 24. Centre for Environmental Economics and Policy in Africa, University of Pretoria, Pretoria.

[3] Deschenes, O. and Greenstone, M. (2006) The Economic Impacts of Climate Change: Evidence from Agricultural Profits and Random Fluctuations of Weather. Social Science Research Network Electronic Paper Collection. Fondazione Eni Enrico Mattei, Milano.

[4] Finger, R. and Schmid, S. (2007) Modelling Agricultural Production Risk and the Adaptation to Climate Change. Munich Personal RePEc Archive. MPRA Paper No. 3943. Paper Prepared for Presentation at the 101st European Association of Agricultural Economists Seminar "Management of Climate Risks in Agriculture", Berlin, 5-6 July 2007.

[5] Mendelsohn, R., Nordhaus, W. and Shaw, D. (1994) The Impact of Global Warming on Agriculture: A Ricardian Analysis. The American Economic Review, 84, 753-771.

[6] Benhin, J.K.A. (2006) Climate Change and South African Agriculture: Impacts and Adaptation Options. CEEPA Discussion Paper No. 21. Centre for Environmental Economics and Policy in Africa, University of Pretoria, Pretoria.

[7] Kabubo-Mariara, J. and Karanja, F. (2006) The Economic Impact of Climate Change on Kenyan Crop Agriculture: A Ricardian Approach. CEEPA Discussion Paper No. 12. Centre for Environmental Economics and Policy in Africa, University of Pretoria, Pretoria.

[8] Eid, H., El-Marsafawy, S. and Ouda, S. (2006) Assessing the Economic Impacts of Climate Change on Agriculture in Egypt: A Ricardian Approach. CEEPA Discussion Paper No. 16. Centre for Environmental Economics and Policy in Africa, University of Pretoria, Pretoria.

[9] Gbetiobouo, G.A. and Hassan R.M. (2004) Economic Impact of Climate Change on Major South African Field Crops: A Ricardian Approach. MSc Agricultural Economics, Faculty of Natural and Agricultural Sciences, University of Pretoria, Pretoria.

[10] Gbetibouo, G.A. and Hassan, R.M. (2005) Economic Impact of Climate Change on Major South African Field Crops: A Ricardian Approach. Global and Planetary Change, 47, 143-152. http://dx.doi.org/10.1016/j.gloplacha.2004.10.009

[11] Sene, I.M., Diop, M. and Dieng, A. (2006) Impacts of Climate Change on the Revenues and Adaptation of Farmers in Senegal. CEEPA Discussion Paper No. 20, Centre for Environmental Economics and Policy in Africa, University of Pretoria, Pretoria.

[12] Jain, S. (2006) An Empirical Economic Assessment of Impacts of Climate Change on Agriculture in Zambia. CEEPA Discussion Paper No. 27, Centre for Environ mental Economics and Policy in Africa, University of Pretoria, Pretoria.

[13] Mano, R. and Nhemachena, C. (2006) Assessment of the Economic Impacts of Climate Change on Agriculture in Zimbabwe: A Ricardian Approach. CEEPA Discussion Paper No. 11, Centre for Environmental Economics and Policy in Africa, University of Pretoria, Pretoria.

[14] Deressa, T. (2006) Measuring the Economic Impact of Climate Change on Ethiopian Agriculture: Ricardian Approach. CEEPA Discussion Paper No. 25, Centre for Environmental Economics and Policy in Africa, University of Pretoria, Pretoria.

[15] Sanghi, A., Mendelsohn, R. and Dinar, A. (1998) The Climate Sensitivity of Indian Agriculture. In: Dinar, A., et al., Eds., Measuring the Impact of Climate Change on Indian Agriculture, World Bank Technical Paper 402, World Bank, Washington DC, 23, 30-32.

[16] Kumar, K. and Parikh, J. (1998) Climate Change Impacts on Indian Agriculture: The Ricardian Approach. In: Dinar, A., Mendelsohn, R., Everson, R., Parikh, J., Sanghi, A. and Kumar, K., Eds., Measuring the Impact of Climate Change on Indian Agriculture, World Bank Technical Paper 402, World Bank, Washington DC, 23, 30-32.

[17] Polsky, C. (2004) Putting Space and Time in Ricardian Climate Change Impact Studies: Agriculture in the US Great Plains, 1969-1992. Annals of the Association of American Geographers, 94, 549-564.

http://dx.doi.org/10.1111/j.1467-8306.2004.00413.x 
[18] Polsky, C. and Esterling, W.E. (2001) Adaptation to Climate Variability and Change in the US Great Plains: A Multi-Scale Analysis of Ricardian Climate Sensitivities. Agriculture, Ecosystem and Environment, 85, 133-144. http://dx.doi.org/10.1016/S0167-8809(01)00180-3

[19] Mano, R. and Nhemachena, C. (2007) Assessment of the Economic Impacts of Climate Change on Agriculture in Zimbabwe: A Ricardian Approach. Policy Research Working Paper 4292, World Bank, Washington DC.

[20] Mendelsohn, R., Dinar, A. and Dalfelt, A. (2003) Climate Change Impacts on African Agriculture. Mimeo, School of Forestry and Environmental Studies, Yale University, New Haven.

[21] Kurukulasuriya, P. and Mendelsohn, R. (2006) A Ricardian Analysis of the Impact of Climate Change on African Cropland. CEEPA Discussion Paper No. 8, Centre for Environmental Economics and Policy in Africa, University of Pretoria, Pretoria.

[22] Kurukulasuriya, P., Mendelsohn, R., Basist, A., Williams, C. and Kogan, F. (2004) Climate Analysis with Satellite versus Weather Station Data. Proceedings of the Session: Impact of Climate Change on Agricultural Productivity and Rural Income at the Allied Social Science Association, San Diego, 3-5 January 2004, 12-30. 